\title{
ULTRASOUND-GUIDED CAUDAL-EPIDURAL BLOCK AND PULSED- RADIOFREQUENCY COMBINED WITH US-GUIDED DRY-NEEDLING TECHNIQUE FOR SEVERE/UNRESPONSIVE LOW-BACK-PAIN MANAGEMENT
}

\author{
P. Fusco', F. De Sanctis², S. Di Carlo³, V. De Paolis², M. Vespasiano ${ }^{3}$, E. Petrucci ${ }^{4}$, F. Marinangeli², \\ W. Ciaschi ${ }^{5}$ \\ ${ }^{1}$ San Salvatore Academic Hospital of L'Aquila, Department of Anesthesia and Intensive Care Unit, L'Aquila, Italy. \\ 2 University of L'Aquila, Department of Life- Health and Environmental Sciences, L'Aquila, Italy. \\ ${ }^{3}$ University of Chieti, Department of Anesthesia- Resuscitation- Intensive and Pain Care, L'Aquila, Italy. \\ ${ }^{4}$ SS Filippo e Nicola Academic Hospital of Avezzano, Anesthesia and Intensive Care Unit, Avezzano, Italy. \\ ${ }^{5}$ Ospedale Fabrizio Spaziani, department of anesthesia- intensive care unit and pain medicine, Frosinone, Italy
}

\section{Background and Aims:}

Ultrasound-guided caudal-epidural block followed by caudal-epidural Pulsed-Radiofrequency (PRF) could provide long-lasting analgesia in severe/unresponsive low-back-pain syndrome. Ultrasound-guided dry-needling could help to detend active myofascial trigger-points of involved muscles

\section{Methods:}

A 57-year-old woman suffering from NSAIDs-related hepatotoxicity and severe low-back-pain caused by L5-S1 disc herniation. Pain, weakness and motor disability were referred to left lumbar region, radiating through the buttock and posterior left leg. Pre-treatment pain assessment was: NRS=8-10, McGill-Pain-Qestionnaire=14 (S9A2V1M2) Roland-Morris-Disability-Questionaire=18. She assumed Oxicodone/Naloxone 20/10 mg/die and Pregabalin $150 \mathrm{mg} / \mathrm{die}$ without pain relief. Informed consent was obtained, routine vital signs were monitored and an active-tip-cannula was inserted under ultrasound-guidance into the epidural space through the sacral hiatus from S4 to S1 level. PRF stimulation was administered at $5 \mathrm{~Hz}$ with a $5-\mathrm{ms}$ pulse width for 600 seconds at $55 \mathrm{~V}$ at $42^{\circ}$ and Levobupivacaine $0,15 \% 15 \mathrm{ml}$ plus Hydrocortisone $50 \mathrm{mg}$ were injected. We also treated the posterior branch of L5 nerve root with PRF.

The following weeks we treated the active myofascial trigger-points of Lumbar Erector Spinae Group, Multifidus, Psoas, Quadratus Lumborum and Gluteal muscles with ultrasound-guided dry-needling.

\section{Results}

During 2-months follow-up period, the patient reported a good-quality analgesia without needing NSAIDs nor opiates. (NRS $=3, M G P Q=5$ and $R M D Q=5$ )

\section{Conclusions:}

Severe low-back-pain syndrome could be effectively treated with caudal-epidural PRF followed by block. These minimally-invasive procedures combined with dry-needling treatment, could prolong analgesia and reduce oral analgesics consumption. Ultrasound-guidance could reduce complications and improve the efficacy and the safety of these procedures.

\section{Keywords:}

Caudal epidural block

Caudal epidural PRF

Dry-needling Low-back-pain

Cho HK, Kang JH, Kim SY, Choi MJ, Hwang SJ, Cho YW, Ahn SH. Changes in Neuroglial Activity in Multiple Spinal Segments after Caudal Epidural Pulsed Radiofrequency in a Rat Model of Lumbar Disc Herniation. Pain Physician. 2016 Nov-Dec; 19(8):E1197-E1209.

C. P. C. Chen, S. F. T. Tang, T.-C. Hsu et al., "Ultrasound guidance in caudal epidural needle placement," Anesthesiology, vol. 101, no. 1, pp. 181-184, 2004 